\title{
MEMÓRIA DA DIMENSÃO (AUTO) FORMATIVA NA ESTEIRA DA CONSTRUÇÃO DE UM TRABALHO DE CONCLUSÃO DE CURSO COM SURDO
}

\author{
A. L. O. AGUIAR ${ }^{1}$, M. A. C. $\operatorname{COSTA}^{2^{*}}$ e J. E. LIMA ${ }^{1}$ \\ ${ }^{1}$ Universidade do Estado do Rio Grande do Norte (UERN) \\ ${ }^{2}$ Rede Estadual de Ensino de Mossoró/RN \\ mifraangelica@hotmail.com*
}

Artigo submetido em abril/2014 e aceito em outubro/2014

DOI: 10.15628/holos.2014.2097

\section{RESUMO}

Discutimos sobre as barreiras e as possibilidades com discentes surdos no Ensino Superior na esteira da construção de um trabalho de conclusão do Curso de Pedagogia da Universidade do Estado do Rio Grande do Norte. Objetiva relatar a experiência de uma educadora, uma intérprete da Língua Brasileira de Sinais, de uma graduanda e um discente surdo do Curso de Pedagogia, Campus Central da Universidade do Estado do Rio Grande do Norte- UERN que, na esteira da construção de um trabalho de conclusão de curso percebem-se aprendentes, rompem obstáculos, quebram grilhões e partem para um trabalho em seu diálogo entre LIBRAS e Língua Portuguesa. Os autores que fundamentam são: Josso (2010); Mantoan (2006); Passeggi (2010); Sassaki (1997); Skliar (2005). Pensa o alcance do ponto de vista do caminho de minimização desses limites quanto aos sujeitos envolvidos, de alerta para os sujeitos acadêmicos ouvintes e surdos, do encolhimento das barreiras físicas, atitudinais, procedimentais e conceituais. Entende a via da aproximação, da escuta, da sensibilidade ao outro, da entrega como porta para a superação das barreiras.

PALAVRAS-CHAVE: (Auto) Formação; Memória; Surdo; Trabalho de Conclusão de Curso.

\section{MEMORY SIZE (AUTO) TRAINING ON MAT CONSTRUCTION OF A WORK OF COMPLETION OF COURSE WITH HARD OF HEARING}

\begin{abstract}
Discussed the barrier sand opportunities with deaf students in higher education in the wake of the construction of a final paper of the Education Course at the University of Rio Grande do Norte. Objectively report the experience of an educator, one interpreter of Brazilian Sign Language, a graduate student and Deaf Education Course, Central Campus of the State University of Rio Grande do Norte-UERN that in the wake of the construction work course completion learners perceive themselves, break barriers, break chains and set off to
\end{abstract}

work on his dialogue between LBS language and the Portuguese language. The authors are: Josso (2010); Mantoan (2006); Passeggi (2010); Sassaki (1997); Skliar (2005). Think about the range of view of the way to minimize these limits for the individuals involved, alert for the deaf and hearing subjects academics, the shrinking of physical barriers, attitudinal, procedural and conceptual. Understands the rapprochement, listening, sensitivity to others, such as door delivery for overcoming the barriers.

KEYWORDS: (Auto) Training. Memory. Hard of hearing. Completion of course work. 


\section{INTRODUÇÃO}

A inclusão é um processo gradual e irreversível como nos afirma Sassaki (1997). Ela acontece lentamente, mas apresenta resultados satisfatórios e seria um retrocesso desejar romper com essa caminhada. No que diz respeito à inclusão, e mais precisamente, no Ensino Superior é uma discussão incipiente e muito reduzida ao número de pessoas com deficiência que tem o acesso a esse nível de ensino.

Este artigo propõe aquecer essa discussão acalorada sobre inclusão no espaço escolar, a fim de viabilizar reflexões, dissensos, dúvidas e alternativas para ser legitimado o ingresso, permanência da pessoa com deficiência na escola, neste caso possibilitar que essa conclua com êxito seu curso.

Tem como objetivo norteador relatar a experiência de uma educadora, uma intérprete da Língua Brasileira de Sinais e de uma graduanda que obtiveram contato, no ano de 2008, com um aluno surdo durante todo seu trilhar no Curso de Pedagogia, Campus Central da Universidade do Estado do Rio Grande do Norte- UERN.

Para Passeggi (2011, p. 148) "o termo experiência, como se sabe, deriva do latim experientia/ae e remete à 'prova, ensaio, tentativa', o que implica da parte do sujeito a capacidade de entendimento, julgamento, avaliação do que acontece e do que the acontece". $O$ ato de experienciar permite ao sujeito conhecer novas ações e/ ou aperfeiçoá-las, sempre na perspectiva do tentar sem cessar, buscar possibilidades, escolhas, caminhos diferentes no seu curso de vida.

$\mathrm{Na}$ esteira da construção de um Trabalho de Conclusão de Curso, percebem-se aprendentes, rompem obstáculos, quebram grilhões e partem para um trabalho em seu diálogo entre LIBRAS e Língua Portuguesa. Os autores que fundamentam são: Josso (2010); Mantoan (2006); Passeggi (2010); Sassaki (1997); Skliar (2005).

$\mathrm{O}$ artigo estará dividido em quatro momentos. No primeiro Memória e Narrativas de Uma Professora- Orientadora do Trabalho de Conclusão de Curso do Discente Surdo, será exposto à narrativa da educadora, a qual orientou o aluno surdo do Curso de Pedagogia da UERN.

No segundo, Interpretar e Aprender Constantemente: Narrar do Fazer do Intérprete de Libras no Momento da Elaboração da Monografia do Educando Surdo será relatado às vivências conflituosas e pacíficas no fazer durante $o$ ato interpretativo da profissional intérprete de LIBRAS na elaboração da monografia do discente surdo de Pedagogia.

No terceiro momento, Impressões e Compreensões de uma Colega de Turma do Curso de Pedagogia, narrativas da aluna, a partir do percurso de experiência de conviver e de participar da tessitura da monografia do acadêmico surdo, ambos da mesma sala de aula.

Possibilitar caminhos e descaminhos na buscar do rumo da inclusão, através de apresentação de experiências, relatos, reflexões, além de buscar um caminho com curvas, espinhos, vislumbrar novas saídas, estradas a seguir, para propor uma educação atenta para o outro, para a diversidade, inclusão, ou seja, preocupada em ser e formar para a humanização. 


\section{MEMÓRIA E NARRATIVAS DE UMA PROFESSORA- ORIENTADORA DO TRABALHO DE CONCLUSÃO DE CURSO DO DISCENTE SURDO}

A ideia da Educação em comunhão, educação mediatizada pelo mundo, o entendimento de que ao educar se é educado, de que o ato cognoscente do educador se faz na cognoscitividade dos educandos, a compreensão do homem inconcluso, consciente de sua inconclusão e seu permanente movimento, nos inspira, sistematicamente, em nosso re-encantamento com a experiência de orientar um Trabalho de Conclusão de Curso (TCC) de um discente com deficiência auditiva.

Freire (1996) é o grande mestre do fazer, a partir dos fazeres e saberes dos homens e mulheres simples, do dia a dia. E nos inspira. Ensina Freire ao pontificar que educar exige risco, o exercício da aceitação do novo e rejeição de qualquer forma de discriminação. Inspira-nos aos caminhos da vida nas plurais dimensões onde se pode aprender e ensinar, a encontrar o outro, a nos colocarmos no lugar do outro.

As práticas educativas podem acontecer em territórios não só físicos, mas nos territórios das biografias dos indivíduos, nas marcas de suas histórias de vida, ao permitirmos que os indivíduos se façam autores em situações que lhes trazem traumas, em experiências excludentes, em situações de negação pelo outro, quando se associam para resistir, lutar e intervir. Alunos e professores têm múltiplos territórios de possibilidades de formação, tanto do ponto de vista das experiências na educação formal, quanto informal. Um desses territórios é o das mãos, do espaço do dizer com os sinais. Mãos que falam, sinais que significam.

Ao mesmo tempo, caminhar na esteira de um TCC exige riscos entre as dificuldades e o caminho na trilha das superações, exige postura ética, exige debruçamento e alteridade. Ao mesmo tempo refletir sobre as controvérsias visívies entre a Política de Educação Especial na Perspectiva da Educação Inclusiva e a prática no chão da sala de aula, no via a vis, no caso deste artigo, com discentes com deficiência auditiva. Entre a possibilidade e a impossibilidade, entre o escrito e o praticado, entre um trabalho para a obtenção da formação exigida pelo Projeto Pedagógico do Curso, entre a formação para a docência e a quebra de barreiras atitudinais, conceituais e procedimentais, entre um curso, uma prática e a acessibilidade ao mesmo.

As narrativas de experiência propostas para este trabalho são como uma mola para nossa vida de educadora e orientadora, experenciadora do exigido aos sistemas de ensino, hoje, um desafio, a saber, alunos com deficência em classes regulares de ensino. Joga-nos para um mergulho sobre nossa formação e nossa prática, permitindo a partir, também, da vivência de suas contradições, o amadurecimento acadêmico, os questionamentos, a reconstrução.

Foi assim que o processo de encontro com o outro se cercou de grande expectativa, pois seria a primeira vez que iríamos construir um Trabalho de Conclusão de Curso com a o primeiro discente surdo na UERN.

O começo exigiu estudo e reflexão sobre a estrutura da Língua de Sinais. A persistência da professora the trouxe a abertura desse espaço junto a outros professores de Pernambuco e da Bahia com quem inicia uma aproximação de troca de experiências e gerenciamento dos anseios.

Assim relembra: 
É certo que não estamos deixando de observar uma série de outros elementos importantes e pertinentes, mas dizemos que participar do meu primeiro Trabalho de Conclusão de Curso foi um processo que exigiu refletir sobre o que está bem mais próximo ao educador que é a sala de aula e as diferentes alternativas e possibilidades no que diz respeito à busca do encontro com os desafios.

Observa-se em sua fala a experiência de presenciar colocar-se diante de si mesma, diante de sua formação inicial e, ao mesmo temo, cotidianamente, seus limites de formação e atestar sobre estar bem próximo do aluno com surdez como uma prática fundamental para ultrapassar as primeiras barreiras, a saber, da linguagem. Em nossa experiência, o discente com surdez, tímido sem acreditar que estava diante de um processo que levaria muitas horas de trabalho. Temos bem claro a "agonia" do discente penetrando pelo mundo das teorias, mas insistindo, olhando dos lados, esperando pelo olhar da intérprete e da professora orientadora como pedindo "socorro" para repetir a explicação, a pergunta, lembra a professora.

A professora encontra, nessa trajetória das descobertas, uma metodologia que a aproximou do discente, para sentir a si e ao outro ao se preocupar com a aproximação e a escuta, por meio da voz do próprio discente, de seus "gritos".

Reconhece, a educadora sobre ir à procura de possibilidades, ser preciso nessa trajetória profissional com discentes com deficiência, exercitar outros lugares, outras situações escolares, outros instrumentos de sala de aula. Pensa, assim, na metodologia, a partir dos cadernos e escritos do discente surdo. Os registros cotidianos de sala de aula para alertar sobre as lacunas, as necessidades. Estes cadernos, e anotações, imprimem-se as marcas do dia a dia, das emoções, dos desafios, de nossas falhas, de nossos limites, nossa memória. Mas, por outro lado, deixam também um documento interessante de reflexão e "refação de nossa prática", assevera a professora.

Foi o caminho tomado por mim quanto ao TCC. Optei por erguer a monografia presencial com a experiência do discente surdo. Preferi o exercício no face a face, interagindo presencialmente, perguntando. Fiquei impressionada com o poder de reflexão do discente. Buscamos na aproximação os elementos para uma autocrítica de nossa prática. $O$ que as situações durante a construção do TCC vão oferecendo de pistas? Que percurso poderia retomar, linha a linha, escrito a escrito, emoção a emoção, palavra a palavra? Que outros caminhos podem indicar esse instrumento fantástico de aprendizagem nos processos de formação?

Dizemos ser importante, na experiência deste trabalho, o percebido sobre como pensam e agem os discentes com deficiência. Interrogamos a formação e a atuação de professores frente à inclusão de discentes com deficiência. Que crenças levamos para a sala de aula, que conceitos, que visão de mundo, que paradigmas educacionais, que tendências pedagógicas?

O que conclui a educadora orientadora sobre o processo vivido a partir dos desafios de hoje? Como pensam e agem diante da presença de um discente não ouvinte? Com baixa visão, com baixa audição, dificuldade de concentração? Vislumbra-se que as ações pedagógicas, em sala de aula, pedem por um olhar afetivo, deseja à dimensão do sensível, querer a prática da superação de nossas barreiras atitudinais, requerem procedimentos coletivos, ações em conjunto e diálogo nos termos de Freire (1996, p.23) ao advogar ao afirmar sobre "quem é formado transforma-se e forma ao ser formado". 
Praticar a experiência do TCC implicou em mexer com minhas lentes, refletir sobre uma cultura historicamente excludente. Da mesma forma, instigou e continuará instigando olhar para as possibilidades, cotidianamente, com essas lentes, penetrar na cultura surda. Ladrilhar e praticar um Trabalho de Conclusão de Curso e, no caso deste trabalho, com discente surdo, aponta para a dimensão do conhecimento de si e do outro, cabe repisar. Impõe uma busca constante, atenciosa e cuidadosa, sobre as necessidades do outro. Solicita sensibilidade profissional quanto ao rever práticas, conviver e viver em sociedade, pensar em um trabalho de participação coletiva.

Apontamos esses desafios, considerando as contradições pela frente vivenciadas como falta de intérprete da Língua Brasileira de Sinais para atender com a qualidade necessária aos discentes surdos tendo a universidade como lugar do Português como primeira língua e os discentes surdos com LIBRAS como primeira língua. Leva para outra importância, qual seja o bilinguismo, urgência da inclusão dos discentes com deficiência na pesquisa e na extensão.

A falta de acesso e domínio das Novas Tecnologias da Informação e da Comunicação (TIC's), necessidade da ajuda na organização e compreensão dos trabalhos escritos, dificuldade de acesso às bibliotecas, à literatura para as pesquisas, falta de vivência de uma vida acadêmica plena com participação em monitoria, eventos científicos, iniciação científica, atividades reduzidas à sala de aula são fatores sinalizadores de cuidado e ações concretas para superação.

O rol dos limites institucionais, por sua vez, não implica em uma melancolia pedagógica e nem, acreditamos, na não busca de projetos e ações concretas, uma vez que o buscar acadêmico, acima, uma vez atendidos traria mais amadurecimento e fundamentação na teoria e na prática a todos e todas.

\section{INTERPRETAR E APRENDER CONSTANTEMENTE: NARRAR DO FAZER DO INTÉRPRETE DE LIBRAS NO MOMENTO DA ELABORAÇÃO DA MONOGRAFIA DO EDUCANDO SURDO}

A construção da monografia do aluno surdo contou com a colaboração da intérprete de LIBRAS. Foram questionadas as sensações, as dificuldades, as conquistas, a partir dessa vivência singular, pois sabemos ser esse o primeiro discente que essa profissional acompanhou. Quando indagado sobre a contribuição dessa experiência para a formação do ser sujeito nos aspectos pessoal e profissional, a intérprete assim organizou e expressou a sua narrativa:

\footnotetext{
A primeira palavra que me vem à cabeça é a palavra confiança de muito peso, e a segunda palavra é responsabilidade. Então essas duas palavras, elas serviram como pilares na construção da monografia do aluno, porque até os dias, de hoje, eu como profissional ainda sofro com a questão da desconfiança do professor com relação ao intérprete de LIBRAS. Se ele, realmente, está passando os conteúdos, quando há, por exemplo, uma pausa do intérprete até mesmo para processar a mensagem que está sendo falada acha que ela não está passando. Veio em minha mente essa grande angústia quando iniciou suas primeiras orientações, da confiança, né. Foi um trabalho muito árduo, não no sentido que ele foi amargo de ser feito, mas árduo no sentido de todo esse peso da responsabilidade e da confiança. Me fez crescer bastante, porque ser a voz de um surdo é muito estrela para uma luzinha de vagalume né, estrela não no sentido de glamour, mas no sentido de que como eu vou usar a minha Língua Portuguesa, que é a minha língua materna transpassar o interior do outro para uma Língua de Sinais, totalmente visual na moral né. Para mim foi muito crescimento, foi um marco, foi uma experiência que certamente contribuiu e muito, me trouxe várias reflexões, no meu modo de falar, no meu modo de traduzir, no meu vocabulário né, e entender como o outro fala, por que tipo como eu seria a voz dele? Seria aquela voz de voz de reivindicar de tal? Aquela voz de
} 
discurso mesmo, qual é a análise do discurso desse sujeito? E a voz da intérprete tem que ser muito em consonância com a sinalização do surdo e então sempre nos cursos eu estou falando isso, o intérprete ele tem que acompanhar a voz do surdo, se o surdo tem uma sinalização lenta o intérprete, normalmente tem que ter uma interpretação lenta também, entender que cada um tem um jeito de falar diferente, um jeito de sinalizar diferente, mas geralmente é isso que acontece né se ele falasse comum ar assim, é assim, é assim eu também interpreto essa voz, o tempo que também teve esse tempo.

$\mathrm{Na}$ fala da intérprete de LIBRAS três pontos foram relevantes. O primeiro refere-se ao fato das palavras confiança e responsabilidade, apresentadas por essa profissional como síntese do momento da construção da monografia do discente. Fica visível alguns entraves a ultrapassar quanto a, inicialmente, conquistar a confiança da professora. A intérprete confessa ser uma situação comum entre os docentes não confiar na interpretação que essa profissional tece. Um segundo elemento interessante na sua narrativa é a questão da "luz de estrela e de vagalume", demonstra à humildade dessa profissional ela se acha pequena diante da imensidão e da responsabilidade de fazer da sua voz, a voz do surdo.

A profissão de intérprete traz imbuída na sua linha do tempo a discussão sobre a confiança que as pessoas têm para com a prática da interpretação. Segundo Kahmann (2008) revela que no período da Reforma "os europeus 'desconfiavam' dos intérpretes, porque, afinal, eles eram índios. Os índios, por sua vez, viam na figura do intérprete uma voz contaminada pelo contato europeu". Denota-se, o papel do intérprete sempre ser colocado em xeque, questionava-se e ainda se pergunta sobre a ação do intérprete e, muitos, ainda não confiam, acham que ele não está interpretando ou não o faz eficazmente. Com isso, ocasiona certo mal-estar entre os intérpretes, refletindo na relação professor, aluno.

Num terceiro ponto verifica-se o respeito com as diferenças, ao ritmo de cada um, nesse olhar para com o outro, sendo enfática ao dizer "se o surdo tem uma sinalização lenta o intérprete, normalmente tem que ter uma interpretação lenta também, entender que cada um tem um jeito de falar diferente, um jeito de sinalizar diferente".

Nos momentos do aluno com o intérprete de LIBRAS com relação às dúvidas, inquietações, dificuldades, para onde ir, o que fazer antes e após as orientações, nos afirmaram:

\footnotetext{
Não. Ele se dirigia a mim apenas para confirmar as leituras, ele tem que ler isso, esse trecho que ele tinha que ler eu explicava que ele tinha que aprender a ler foi um processo de independência. Na verdade, que eu quis passar para ele no sentido era um momento decisivo ele, a partir dali ele seria um pedagogo e a partir dali tinha que ter independência de pegar um livro na biblioteca, fazer um trecho que ao qual mesmo com termos profundos, mas com outras palavras que ele conhecesse que ele fosse grifando e eu ajudava nesse sentido.
}

Percebemos a intérprete como sendo, realmente uma profissional comprometida com o crescimento intelectual e social do aluno, à medida que ela interpretava pensando no nível exigido para um Trabalho de Conclusão de Curso. Ela previa a relevância dessa ação no aprendizado de novos significados na leitura em Português que é diferente de LIBRAS, a estrutura das frases é diferente, ela instigava também, a partir das orientações o discente experimentar desafios, situações de independência e autonomia.

De acordo, com Sassaki (1997) "autonomia é a condição de domínio no ambiente físico e social, preservando ao máximo a privacidade e a dignidade da pessoa que a exerce [...] 
Independência é a faculdade de decidir sem depender de outras pessoas, tais como: membros da família ou profissionais especializados". Vislumbrava-se formar sujeitos ativos, com gostos e concepções próprias, os quais decidem suas próprias questões, não depende totalmente de terceiros.

Foi indagado se a intérprete havia percebido um avanço significativo no aluno com esse trabalho de estimular a independência e autonomia do discente. A intérprete com propriedade afirmou:

\begin{abstract}
Houve, houve né. Em questão de organização, assiduidade muito com a pesquisa né e o interessante que eu vivi as mesmas angústias, a mesma ansiedade, a mesma preocupação que, ai meu Deus, ainda tem o 20 Capítulo, ainda tem o 3으, estamos concluindo. Então foram as mesmas sensações, era eu que estava construindo. No dia da apresentação, também foi o mesmo nervosismo de que era uma banca que estava ali presente, eu tinha que traduzir com tamanha fluência, acompanhar o mesmo ritmo da monografia. No ato da colação também foi um momento de ansiedade, de missão cumprida né, de dizer eu conclui esse trabalho né, as sensações foram muito parecidas talvez ele não tenha demonstrado tanto, mas eu senti as mesmas coisas, né aquele alívio e aquela angústia de início como que vai ser, será que eu vou conseguir, será que eu vou chegar até lá. Contava os dias, os dias não passavam, contava as horas, não passava, quanto mais contava mais longe ficava, mas as sensações foram às mesmas.
\end{abstract}

Foi demonstrado à sensibilidade e a parceria da intérprete com o educando surdo ao sentir as mesmas angústias, preocupações durante todo o processo da monografia. Viver cada momento com o educando, se sentir no lugar do outro, ela se sentiu pertencente também nessa experiência. Ela sentiu ao final do resultado da monografia, a sensação de "missão cumprida".

Foi questionado sobre da oportunidade de atender um aluno surdo no período de tessitura da monografia, se ela mudaria suas práticas, saberes, formação, a partir da experiência adquirida. Ela assim respondeu “Eu não sei. Essas respostas eu acho que só teria se eu vivesse de novo, porque o intérprete, a profissão é imprevisível não tenho nada pronto para dizer se eu mudaria ou se eu não mudaria. Então eu não teria nada a dizer". Ela realmente compreende a profissão de intérprete como de responsabilidade e enxerga cada surdo como ser único, as vivências como momentos únicos impossíveis de serem estimadas no futuro, revela que "a profissão é imprevisível não tenho nada pronto".

Josso (2008, p. 84) "ir ao encontro de si visa à descoberta e à compreensão de que viagem e viajante são apenas um". O ato de narrar e propriamente a construção das narrativas da intérprete de LIBRAS retrataram um pouco do momento de encontro consigo mesma e de rememorar a tensão e emoção da confecção da monografia do aluno surdo, a mobilização dos seus saberes, a necessidade de aprofundar os estudos, o vocabulário e exigir do aluno também um nível acadêmico na sinalização de LIBRAS, embora saiba a língua de sinais não deter de sinais diversificados, muitos significados.

\title{
4 IMPRESSÕES E COMPREENSÕES DE UMA COLEGA DA TURMA DO ALUNO SURDO NO CURSO DE PEDAGOGIA
}

Muitas são as lembranças do momento da graduação. Convivi com o aluno surdo durante quatro anos do Curso de Pedagogia da Universidade do Estado do Rio Grande do Norte (UERN). Situações de desafios, dificuldades, oportunidades, mudanças nas aulas, nas estratégias 
metodológicas, trabalhos, avaliações escritas, na interação com os professores, funcionários e alunos ouvintes.

Várias foram às experiências marcantes desde o ingresso na universidade até o momento do término do curso. Recordo-me que a princípio todos estanhavam o fato de termos um aluno surdo, tínhamos o desejo de ajudar, fazê-lo participar das aulas, mas a barreira comunicacional era o maior empecilho, pois inviabilizava a troca de experiências, interações entre a cultura surda e ouvinte.

Mesmo o discente dispondo no horário contrário da aula de um atendimento mais específico a sua necessidade, no caso a auditiva, sentia a necessidade de dominar a Língua Brasileira de Sinais (LIBRAS), pois precisa manter a comunicação. Então, algumas pessoas da turma foram cursar LIBRAS I, posteriormente LIBRAS II. Cursos com possibilidade de conhecer a comunidade surda, a Língua de Sinais, a escrita e a maneira de comunicação com o aluno surdo.

Trilhei por caminhos que me conduziriam a inclusão. No período da graduação procurava estudar, pesquisar, saber mais sobre o paradigma da inclusão, os tipos de deficiência, as estratégias metodológicas para se ensinar crianças, jovens e adultos com necessidades especiais. Vou buscado participação em encontros, seminários, congressos, minicursos, cursos e leituras sobre o tema.

A participação no projeto de pesquisa do Programa Institucional de Bolsa de Iniciação Científica- PIBIC, cujo título Política de educação inclusiva, formação e prática: a relação entre o modelo de educação inclusiva e as práticas educativas desenvolvidas nas escolas públicas de Mossoró/RN (2009-2011), direcionou uma discussão para a Educação Especial na Perspectiva da Educação Inclusiva voltada para as estratégias metodológicas que as professoras da escola pública de Ensino Básico utilizam para ensinar crianças com deficiência.

O projeto PIBIC A Perspectiva (Auto) biográfica: um Retrato dos Saberes e Experiências da Inclusão de Alunos Surdos da UERN (2011 e 2012) objetivou conhecer as narrativas das experiências acadêmicas dos alunos surdos do Curso de Pedagogia, Campus Central da UERN. Algumas evidências anunciadas pelos discentes nessa pesquisa: barreiras comunicacionais é ainda um grande problema, a participação tímida ou inexistente dos surdos como bolsistas de projetos de pesquisa e nos cursos de extensão, número reduzido de intérpretes.

Embora todas as vivências tenham contribuído para edificar minha formação humana e profissional, conviver com o aluno surdo foi o maior aprendizado, considerando o entendimento como um professor, nos ensina os sinais de LIBRAS, nos surpreendia com seu esforço, zelo e dedicação aos estudos. Tínhamos diariamente um laboratório de LIBRAS, a oportunidade de aprender a falar com as mãos, o surdo nos ensinava com calma e vibrava quando percebia que um ouvinte se interessava em aprender uma nova língua.

Um das experiências que desejo compartilhar com mais aprofundamento é da elaboração de sua monografia de conclusão de curso, acontecido no 8 o período do Curso de Pedagogia, no final de 2011 e início de 2012. Ao total foram 60 horas de encontros para orientação, sempre no horário da tarde e respeitando a quantidade de horas dobradas para atender a necessidade especial do aluno. Todas as orientações diárias duravam duas horas, portanto uma hora a mais dos demais.

Ao meu olhar pude perceber que a docente orientadora se preocupou em possibilitar a inclusão desse aluno em todas as situações, sempre contando com a intérprete de LIBRAS, quando 
essa não podia está a professora-orientadora e a colega auxiliavam a interpretação. Foi respeitada a estrutura de LIBRAS na escrita da monografia, sua semântica, bem como o objeto de estudo não ser algo distante do aluno, mas sua própria experiência no Estágio Supervisionado II do Curso de Pedagogia.

A professora juntamente com a intérprete, o aluno surdo e a discente decidiam o melhor para a orientação, sempre com o cuidado de se colocar no lugar do outro, foi realizado um cronograma como era realizado para os demais orientados da docente, então o aluno surdo também haveria de cumprir prazos.

A intérprete de LIBRAS buscava sempre traduzir e interpretar com cautela, calma, pois a construção de uma monografia exige paciência na interpretação para o discente surdo entender e cumprir o que era solicitado pela orientadora, por isso, a comunicação, a relação pedagógica, a interação, diálogo foram primordiais para esse processo.

A minha participação foi de auxiliar a professora, a intérprete e ainda o aluno surdo. Nesse período também participava do PIBIC sobre surdez. Contribui ajudando o aluno em algumas compreensões de atividades, anotava as recomendações, tarefas que a orientadora, falava e realizava pequenas interpretações.

Percebi o educando surdo sempre disposto a continuar na caminhada da elaboração do seu Trabalho de Conclusão de Curso (TCC), pois a orientadora, intérprete e colega de turma se mostravam solicitas e pacientes. $\mathrm{O}$ aluno era pontual aos encontros, era assíduo, interagia bem e estava contente de poder apresentar a sua experiência exitosa de estágio supervisionado no Centro Estadual de Capacitação de Educadores e Atendimento ao Surdo (CAS).

Defendemos, por fim, em comunhão com Skliar (2005, p. 188) "escola inclusiva é sinônimo de escola significativa. No caso dos surdos, por exemplo, a questão não é: 'os surdos têm o direito a estudarem na escola regular, mas, sim: os surdos têm direito a uma educação plena e significativa". Acreditamos no potencial do surdo, ele é um ser de competências, possui o seu direito de ingressar, frequentar e concluir o Ensino Básico, Secundário, realizar uma Pós-graduação e estar no mercado de trabalho. Necessita serem oferecidas as mesmas oportunidades a todos.

Essa experiência empreendeu num grande desejo de estudar e pesquisar sobre a inclusão, delineando a investigação para a Relação Pedagógica Professor, Intérprete de LIBRAS e aluno surdo do Curso de Pedagogia da UERN, sendo esse o projeto de pesquisa do Programa de Pós-graduação em Educação (POSEDUC), o objetivo norteador propõe analisar a relação pedagógica professor, intérprete de LIBRAS e aluno surdo do Curso de Pedagogia da UERN, com vistas ao processo inclusivo de ensino e aprendizagem.

\section{CONSIDERAÇÕES FINAIS}

Este trabalho foi mobilizado pelas discussões e preocupação de promover a inclusão dos alunos surdos e fazer com que esses tenham as mesmas oportunidades dos ouvintes durante o curso de graduação até o seu término quando se culmina com a escrita da monografia.

O aluno surdo necessita além de uma professora - orientadora, de um atendimento da intérprete de LIBRAS, precisa de uma profissional competente na área a ser estudada e na 
pesquisa, proposta para a feitura da monografia, bem como de uma intérprete, a qual auxiliará a professora ouvinte que domina LIBRAS e o aluno surdo.

Foi um caminho árduo, difícil, mas uma estrada possível, uma via transitada com cuidado, paciência, persistência, zelo, respeito, dedicação, compromisso e esperança de sonhar e de nunca desistir, como disse Freire (2008) "a esperança é necessidade ontológica" ela não pode ser vista como um desejo vão, mas como uma ação, uma prática.

Carlos Drummond de Andrade nos faz refletir com um dos seus poemas, oqual confessa que "no meio do caminho tinha uma pedra". Podemos fazer uma analogia com a nossa experiência de edificação da monografia do aluno surdo, pois o caminho por nós trilhado, e principalmente, do educando, foi de pedras, desde seu ingressar na universidade pelo processo lento, mas contínuo que é o da inclusão. No entanto, com todos os obstáculos o discente conseguiu superá-los e concluir de maneira regular o Curso de Pedagogia da UERN, sendo o primeiro surdo do Rio Grande do Norte a concluir a graduação em uma universidade pública.

Essa vivência, certamente, contribuiu para a formação de todos os sujeitos envolvidos nesse processo de realização da referida monografia. Sendo uma aprendizagem não apenas para o educando que estava no processo educativo, em nível de ensino superior, mas também de aprendizagens agregadas à formação e a prática da professora- orientadora, da intérprete de LIBRAS e ainda da colega de turma.

Esse artigo permitiu-nos revisitar as nossas lembranças, recordações e vislumbrar cada vez mais práticas inclusivas, de olhar atento para o outro, para as suas necessidades, pois entendemos a inclusão como um processo contínuo, ativo e não de acomodação, passividade.

Tem-se que buscar a formação tendo ou não um aluno com deficiência, pois a partir da vivência dessas experiências há uma porta para a formação continuada, para a conquista de outros saberes e, mais ainda, para a ampliação do conhecimento inicial, de pesquisa exploratória sobre inclusão, sobre os tipos de deficiência. Desejamos a sensibilização com essas inquietudes e reflexões de todos os educadores, intérpretes, enfim os sujeitos, envolvidos nesse processo de ensino e de aprendizagem.

\section{REFERÊNCIAS BIBLIOGRÁFICAS}

1. Faria, E. M. B. Cavalcante, M. C. B. (organizadoras). Língua Portuguesa e Libras: teorias e práticas - João Pessoa: Editora Universitária da UFPB, 2011.

2. Freire, P. Pedagogia da autonomia: saberes necessários à prática educativa. 2 ed. São Paulo: Guerra e Paz, 1996.

3. Josso, M. C. A experiência de vida e formação. 2 ed. rev. e ampl. Natal, RN: EDUFRN, São Paulo: Paulus, 2010. (Coleção Pesquisa (auto) biográfica \& Educação. (Série Clássicos das Histórias de Vida).

4. Passeggi, M. C. A experiência em formação. Educação, Porto Alegre, v. 34, n. 2, p. 147-156, maio/ago. 2011.

5. Sassaki, R. Inclusão: construindo uma sociedade para todos. Rio de Janeiro: WVA, 1997.

6. Skliar, C. A surdez: um olhar sobre as diferenças. Porto Alegre: Mediação, 3 ed., 2005. 